\title{
EDUCAÇÃO FÍSICA, ENSINO MÉDIO E JUVENTUDE: VAMOS FA- LAR SOBRE CRISE?
}

\author{
Gabriel Carvalho Bungenstab \\ Universidade Estadual de Goiás, Goiânia, Goiás, Brasil
}

\begin{abstract}
Resumo
Este ensaio se insere no debate atual que procura analisar as relações que são estabelecidas entre a Educação Física, o Ensino Médio e a juventude no cenário brasileiro. O objetivo é mostrar, a partir do diagnóstico da crise da instituição escolar, que as atuais propostas/reformas educacionais dirigidas ao Ensino Médio afetam também a discussão a respeito da juventude e da Educação Física escolar, fazendo com que elas também iniciem um processo de crise. O texto sugere, com um olhar epistemológico, que a inserção do Ensino Médio dualista traz o retorno de uma visão de jovem pautada pela perspectiva geracional e anuncia uma nova era da crise de legitimidade da Educação Física dentro do contexto do Ensino Médio.

Palavras-chave: Ensino Médio. Juventude. Educação Física. Crise.
\end{abstract}

\section{PHYSICAL EDUCATION, HIGH SCHOOL AND YOUTH: LET'S TALK ABOUT CRISIS?}

\begin{abstract}
This essay is inserted in the current debate that seeks to analyze the relationships that are established between Physical Education, High School and youth in the Brazilian scenario. The objective is to show, from the diagnosis of the crisis of the school institution, that the current educational proposals / reforms addressed to the High School also affect the discussion about youth and Physical Education, causing them also to initiate a crisis process. To this end, the text suggests, with an epistemological view, that the insertion of the dualistic High School brings the return of a young vision guided by the generational perspective and announces a new era of the crisis of legitimacy of the Physical Education.
\end{abstract}

Keywords: High School.Youth. Physical Education. Crisis.

\section{EDUCACIÓN FISICA, ESCUELA SECUNDARIA Y JUVENTUD: VAMOS HABLAR SOBRE CRISIS?}

\section{Resumen}

Este artículo se inserta en el debate actual que busca analizar las relaciones que se establecen entre la Educación Física, la Escuela Secundaria y la juventud en el escenario brasileño. El objetivo es mostrar, a partir del diagnóstico de la crisis de la institución escolar, que las actuales propuestas/reformas educativas dirigidas al Escuela Secundaria afectan también la discusión sobre la juventud y la Educación Física escolar, haciendo que ellas también inicien un proceso de crisis. El texto sugiere, con una mirada epistemológica, que la inserción del Escuela Secundaria dualista trae el retorno de una visión de joven pautada por la perspectiva generacional y anuncia una nueva era de la crisis de legitimidad de Educación Física dentro del contexto del Escuela Secundaria.

Palabras clave: Escuela Secundaria. juventud. Educación Física. Crisis. 


\section{Introdução}

Este ensaio se insere no debate atual que procura analisar as relações que são estabelecidas entre a Educação Física (EF), o Ensino Médio (EM) e a juventude. ${ }^{1}$ Como bem ressaltou Bungenstab (2016, p. 15), Dayrell (2007) foi um dos primeiros pesquisadores brasileiros a alertar sobre a crise que afeta o EM diante dos jovens estudantes que, cada vez mais, estão realizando críticas sobre a importância da instituição escolar em suas vidas. Desse modo, o objetivo deste texto é compreender como esta crise também afeta a discussão a respeito da juventude e da EF escolar, fazendo com que essas também comecem a entrar em crise.

O estabelecimento de uma crise, de acordo com Fensterseifer (2001), surge a partir do momento que a comunidade (senso comum e/ou científica) passa a olhar para algo que fora construído coletivamente de maneira crítica e reflexiva. A crise, nesse sentido, sempre é contextualizada historicamente representando uma ruptura que pode ser econômica, política e/ou educacional. Segundo Bastien (1989), Karl Marx foi o primeiro a analisar a relação intrínseca existente entre o termo "crise" e o capitalismo, apontando a necessidade de que a sociedade capitalista tem de criar crises para a manutenção do poder e das relações de consumo. Para Bastien (1989, p. 13):

O leque de possibilidades de desfechos para uma crise histórica é consideravelmente restringido, e o momento subjetivo que leva muitos dos seus atores a crerem que nesse momento de descontinuidade, de virtual suspensão dos processos de reprodução social vigentes, «tudo é possível», revela-se crença ideológica.

Contudo, para Fensterseifer (2001), refletir sobre possíveis crises não é apenas realizar um diagnóstico apontando algumas descontinuidades, mas sim formular possíveis saídas para superá-las. No cenário brasileiro, como bem ressaltaram Bungenstab e Lazzarotti Filho (2017), o governo de Michel Temer propôs saídas para a crise do EM com a criação da nova Base Nacional Curricular Comum (BNCC) e de uma reforma educacional. Essas saídas, segundo os autores, favorecem a reprodução social vigente e causam impactos negativos na compreensão das juventudes e da presença da EF nesta etapa de ensino. Nesse sentido, Molina Neto et al. (2017) afirmam que a reforma do EM e as alterações da BNCC dão início a uma crise sem precedentes na EF brasileira.

As possíveis saídas para essa crise apresentadas pelo governo resultam em uma composição maléfica para a juventude brasileira e para a $\mathrm{EF}^{2}$, uma vez que a torna um elemento estranho (incoerente) dentro do EM. Desse modo, as propostas absurdas para este novo EM fazem com que tanto a Educação Física como a categoria juventude se tornem elementos incongruentes dentro deste contexto. Tal composição, não só prejudica a Educação Física enquanto componente curricular, como também desconsidera o jovem enquanto sujeito social.

Portanto, este texto seguirá um itinerário reflexivo na tentativa de entender o que significa falar em crise: 1) no âmbito da discussão sobre juventude, 2) no âmbito do Ensino Médio e 3) no âmbito Educação Física. Por fim, tentaremos demonstrar que existem outras possíveis saídas para a crise que podem legitimar a presença da Educação Física no Ensino Médio e reconhecer o jovem como sujeito histórico-social.

\footnotetext{
${ }^{1}$ Este ensaio nasce a partir da tese de doutorado defendida pelo autor no Programa de Pós-Graduação em Sociologia da Universidade Federal de Goiás.

${ }^{2}$ Fato recentemente apontando pelos pesquisadores que publicaram no dossiê da revista Motrivivência. Os artigos deste dossiê analisaram profundamente os documentos legais da reforma do EM. Reconhecemos a importância destas análises, contudo, o foco deste texto é refletir sobre a consequente crise gerada pela criação destes documentos.
} 


\title{
O que significa falar em crise no âmbito da(s) juventude(s)?
}

Rousseau (1973) foi o primeiro pensador a se debruçar sobre o debate a respeito das concepções de juventude, separando as etapas da vida do homem em fases, quais sejam: a criança, o jovem e o adulto. Já Comte (1983) utilizou as etapas da vida para defender a ideia do progresso linear considerando que a juventude se situa em uma geração específica que se relaciona com aquilo que fora preservado por gerações anteriores. Nessas primeiras abordagens sobre a juventude, podemos afirmar que ela se configurava apenas como uma etapa da vida dos indivíduos (BUNGENSTAB, 2016, p. 38).

Já em meados da década de 1920 as pesquisas sobre a juventude foram influenciadas pelos estudos da Escola de Chicago e pelos pesquisadores da Sociologia funcionalista. Esses estudos consideraram os jovens como sujeitos que estavam passando por uma fase de transição para a idade adulta, ressaltando (por meio de pesquisas etnográficas) os riscos de os jovens assumirem comportamentos desviantes, tornando-se, consequentemente, problemas sociais (BUNGENSTAB, 2016). Para Souza (2010), é a partir da década de 1950 que o debate conceitual sobre os jovens se polariza entre as perspectivas geracionais e classistas. Segundo Bungenstab (2016, p. 39):

\begin{abstract}
Para Pais (1993), os defensores da corrente classista consideram que a transição dos jovens para a vida adulta sempre irá ocorrer baseadas em questões de reproduções classistas. Assim, se é jovem e, também, se pertence a uma classe. Todas as manifestações e ações de grupos juvenis são analisadas sob o ponto de vista da classe pertencente por esses jovens. Nesse sentido, jovens pertencentes a diferentes classes sociais tem diferentes modos de viverem suas juventudes. Isso faz com que as análises se voltem, quase sempre, a discussão a respeito da resistência (ou não resistência) juvenil diante das culturas dominantes. O apelo político dá o tom nas pesquisas que se empregam desta corrente. No entanto, a corrente classista apresenta limitações ao acreditar que todas as questões juvenis são resultantes de processos de dominação e de posicionamento de classe.
\end{abstract}

No cenário brasileiro, como se apresenta o debate a respeito da condição juvenil? No Brasil, inúmeros são os estudos que versam sobre os jovens. Esses estudos se dirigem para diferentes campos, discutindo sobre a juventude e relacionando-a com violência, educação, políticas públicas, saúde, trabalho e práticas corporais. Para Groppo (2000; 2004), a juventude é uma realidade social e não uma mistificação ideológica, ou seja, ela não pode ser pensada como uma construção imaginária ou como um rótulo que surge com a simples função de manipulação ideológica. Como realidade social, a juventude é uma criação histórica e não uma invariante universal. Desse modo, é preciso relacioná-la a outras categorias sociais como: a classe social, etnia, raça, religião e condição urbana. (BUNGENSTAB, 2016). Segundo Dayrell (2010), a mudança de paradigma conceitual sobre a juventude se dá a partir do momento em que os jovens passam a serem vistos mais como problemas sociológicos e menos como problemas sociais. Nesse sentido, Bungenstab (2016, p. 55) afirma que:

A juventude é, antes de tudo, uma construção histórica [...] Dayrell realiza a crítica ao monopólio cultural que as instituições modernas detinham até então no que tange a sua relação com a juventude. Dayrell acredita que as instituições (e a escola) perderam esse monopólio devido a um aumento da cultura de massa e das sociabilidades juvenis que tem surgido no espaço-tempo do cotidiano. A primeira definição de juventude apresentada por Dayrell (2003) tenta compreender os jovens como sujeitos sociais que constroem um determinado modo de ser jovem. Dessa forma, Dayrell (2003) acredita que a juventude é tanto uma condição social como também um tipo de representação. Assim, se existe um aspecto geral, pautado por transformações físicas e mudanças psicológicas, há um caráter mais local dado como essas modificações acontecem em cada sociedade específica e isso se refere às condições sociais (classes), culturais e de gênero. Para o sociólogo brasileiro, então, a juventude é par- 
te de um processo amplo da constituição dos sujeitos, mas que é acompanhada por especificidades que marcam a vida de cada indivíduo ou grupo.

Com a discussão a respeito do conceito sociológico de juventude, podemos afirmar que esta passou por, pelo menos, dois momentos de crise. O primeiro deles relacionado ao deslocamento do debate da juventude como geração e/ou fase da vida problemática para a consideração de que a juventude deveria ser vista, também, por suas características classistas. O segundo momento de crise se dá a partir do ponto em que se compreendem as limitações de entender e analisar esses indivíduos apenas pelas perspectivas geracionais procurando, assim, compreender os jovens enquanto categoria social.

Ambos os momentos de crise surgiram atrelados às perspectivas sociológicas críticas, sobretudo, a partir do entendimento de que a visão sobre o jovem era limitadora e não permitia compreender esses sujeitos além de uma fase de vida transitória. Ou seja, para além dos aspectos gerais, as teorias passaram a valorizar os contornos locais que, também, caracterizam esta categoria. Apesar desse entendimento, as propostas de reformas educacionais do atual governo parecem, ainda, defenderem uma noção de juventude focalizada em aspectos gerais, fato que remonta a uma noção geracional que busca encaixar todos os jovens em uma mesma posição desconsiderando, assim, os determinantes locais. ${ }^{3}$ Considerar a juventude a partir deste viés significa a manutenção desta crise (solucionadas pelas teorias sociológicas) que potencializa as desigualdades construídas historicamente ao invés de minimizá-las.

\section{O que significa falar em crise no Ensino Médio?}

A discussão sobre o EM brasileiro está sendo pautada por dois movimentos que apontam a necessidade de analisar esta etapa de ensino de maneira crítica. O primeiro deles, mais geral e que sofre influências dos pensadores europeus, se pergunta pela legitimação da escola enquanto uma instituição oriunda da modernidade. O segundo movimento, mais específico ao cenário brasileiro, se interessou em discutir a respeito da crise de identidade do EM.

Segundo Bungenstab (2016), alguns pensadores europeus acreditam que a sociedade atual não consegue se adequar a instituição escolar, sobretudo pelo fato de esta última ainda estar enraizada nos moldes de uma sociedade sólida e homogênea. Para Dubet (1994), a escola está vivenciando o fim de um modelo de organização concebido como ferramenta para institucionalizar valores. No entanto, não se pode afirmar que a escola não funciona mais e que chegou o seu fim, até porque o sociólogo francês ressalta que a escola continua funcionando, porém não mais como uma instituição. Para ele, a escola deve funcionar de forma democrática, garantindo totais condições para todos os alunos. Bauman $(2005,2009)$ alimenta esta posição [...] e acredita que o conhecimento durável transmitido pela escola que levaria os estudantes a conquistarem posições seguras no futuro tem perdido espaço e, nesse ponto, a existência e a importância da escola é constantemente colocada em xeque.

No cenário brasileiro, Bungenstab (2016) afirma que Dayrell (2007) e Carrano (2011) aparecem como representantes da ideia de um possível "descompasso" entre os jovens estudantes e a escola. Para eles, a escola tem sofrido, cada vez mais, influencia dos jovens que chegam aos bancos escolares. Tal fato contribui para a redefinição dos sentidos das aprendizagens dos estudantes, sobretudo, aqueles que se referem ao conhecimento para o futuro. Nesse sentido, Dayrell (2007) acredita que os jovens estudantes ajudam a escola a entender a importância não apenas de se trabalhar com aprendizagens que só farão sentido em um momento

\footnotetext{
${ }^{3}$ Foi veiculada na mídia uma propaganda do governo federal que apresenta os "pontos positivos" da reforma educacional do EM. Nesta propaganda, a mensagem passada é aquela de que todos os jovens (independente de sua região, classe e etnia) poderão ter as mesmas condições educacionais. Este fato aumenta a ideia de que os jovens constituem uma geração única e que os determinantes locais não são importantes.
} 
futuro, mas também de se ensinar conteúdos enraizados ao contexto do cotidiano juvenil, ligados, então, ao presente.

Como bem destacaram Bungenstab (2016) e Bungenstab e Lazzarotti Filho (2017), a instituição escolar procurou encontrar saídas para a sua crise de identidade, principalmente, apostando nos variados modelos de formações e na ideia da diversidade.

As discussões que permeiam o cenário brasileiro tentam entender a identidade desta etapa de ensino no que tange a presença do ensino propedêutico, da formação profissional e/ou de uma formação mais geral. Autores como Reis (2012) e Moehlecke (2012) defendem que a busca pela identidade do EM considere a possibilidade de trabalhar com as diferentes formações a partir de um currículo mais flexível e de uma compreensão melhor a respeito dos jovens que frequentam este espaço.

Como destacado por Carrano (2017), o governo federal, com a reforma do EM e a mudança da BNCC, demonstra que fez uma interpretação da crise totalmente autoritária, desconsiderando o diálogo com outros setores da sociedade. O retorno da concepção dualista do EM e da hierarquização das diferentes disciplinas estão presentes no texto da reforma e anunciam uma saída para a crise que, como situado por Bastien (1989), reforça as desigualdades sociais e aumenta a manutenção dos projetos neoliberais no que tange a educação.

\section{O que significa falar em crise no âmbito da Educação Física?}

A constituição da EF enquanto campo acadêmico, que tem na produção do conhecimento e na prática pedagógica sua fundamentação, se deu e se dá a partir de momentos de crises que foram muito discutidos pela própria área. Porém, enquanto objeto de reflexão e compreensão para mudança de práticas pedagógicas e curriculares, há dúvidas sobre o alcance da produção do conhecimento da área, sobretudo em relação ao "chão da escola". Compreendo, de acordo com Fensterseifer (2001), que a EF passou por dois "momentos" de crise e que as atuais propostas reformistas do EM anunciam a entrada da EF em um terceiro momento de crise. A ideia, a seguir, é apresentar estes momentos com foco, especialmente, no último deles.

O primeiro "momento" de crise da EF se deu junto a própria crise da modernidade. Nesse sentido, como ressaltado por Lima (2000), a EF entra em crise ao se perguntar sobre qual a sua identidade e sua função social. Fensterseifer (2001) expõe que, entre as décadas de 1970 e 1980, a EF passou por mudanças estruturais, gerando um descompasso entre o novo e o estabelecido até então. Lima (2000) retrata que, no período final da década de 1980 e início dos anos 1990, a presença de uma crise político-ideológica referia-se a busca pelo entendimento do papel da área perante a sociedade. Tal fato foi influenciado pelo contexto histórico, social e político brasileiro (fim da ditadura militar e a reabertura política). Nessa conjuntura as teorias críticas passaram a auxiliar as produções da área, subsidiando pesquisadores que buscaram romper com antigos conceitos vigentes, como a técnica racionalizada e o paradigma da aptidão física. No que tange à crise de identidade, vale destacar as vertentes científicas e pedagógicas que travaram um debate a respeito da cientificidade da área, ou seja, da necessidade ou não de a EF "virar" ciência.

O segundo "momento" de crise parece nascer a partir do século XXI e, como descrito por Almeida, Bracht e Vaz (2012), é caracterizado por uma reconfiguração no que tange ao entendimento das matrizes teóricas. Outrora, o campo da EF delimitava suas contribuições e relações epistemológicas a partir das matrizes positivistas, materialistas e fenomenológicas; essa classificação tornou-se "[...] insuficiente para caracterizar a complexidade, as nuanças e a diversidade teórica e política presente atualmente no âmbito de nossa discussão epistemológica" (ALMEIDA; BRACHT; VAZ, 2012, p. 243). 
Almeida, Bracht e Vaz (2012) apontam que o debate epistemológico é marcado por duas concepções distintas: os modernos e os "pós-modernos". Os modernos se pautam pelas ideias de luta de classes e exploração, apontando que o posicionamento político se sobrepõe a própria ciência e apresentam-se como aqueles que possuem alto grau de criticidade ao que tange a função social da EF. Os "pós-modernos" fazem outra leitura da realidade entendendoa como "[...] uma reescrita de alguns traços reivindicados pela própria modernidade". (ALMEIDA; BRACHT; VAZ, 2012, p. 249). Nesse sentido, a sociedade torna-se mais complexa, com a presença de questões microssociais, com problemas mais específicos e debates diferentes. A presença da linguagem passa a ser igualmente importante para a compreensão do mundo.

Inserido nesse debate, Fensterseifer (2009) propõe que a EF desenvolva novas possibilidades de esforços comunicativos. Primeiro, segundo ele, deve-se levar em consideração o caráter histórico-cultural dos conhecimentos. É necessário apontar que há mais de um caminho para se enxergar a realidade. Fensterseifer (2009) apresenta que por muito tempo a visão de verdade era postulada por um olhar positivista de ciência, que repercutiu inclusive no modelo de aulas presentes nas escolas e, no que tange ao campo, a dicotomia teoria-prática se estabeleceu, deixando de legado a transmissão de saberes sem espaço para contestação, além dos métodos pautados pela reprodução e memorização de conteúdos. Nesse contexto, a atividade epistemológica era velada e não permitida aos profissionais de EF se restringindo, apenas, ao seleto grupo de intelectuais. Segundo Fensterseifer (2009, p. 211), ainda ocorrem problemas relacionados à divergência da visão do campo entre aqueles que se encontram no contexto da pesquisa e aqueles que se encontram em atuação em outros âmbitos. Os primeiros acabam por apresentar uma "postura 'denuncista' da realidade".

O primeiro e o segundo "momento" de crise da EF estavam relacionados à própria crise da modernidade e a sua relação dissonante entre teoria/prática. As saídas para esses momentos estão ligadas à produção do conhecimento dentro da própria área e a renúncia diante das classificações epistemológicas reducionistas. Vale ressaltar, segundo Almeida e Vaz (2010, p. 13), que "A educação física, portanto, não somente aplicaria conhecimento, mas também o produziria". Hoje, o que significa falar em crise da EF? Aliás, faz sentido falar em uma crise da EF? Atualmente, a "crise" na EF se direciona a formulação de perguntas a respeito da legitimidade desta disciplina dentro da escola, mais precisamente no EM. A configuração política atual do EM torna difícil que a EF se legitime na escola a partir de aspectos críticos?

Na tentativa de sonorizar esse "diálogo de surdos", a revista Motrivivência publicou, no ano de 2017, um dossiê temático com a seguinte pergunta: "Há lugar para a Educação Física neste novo ensino médio?" Para Gariglio, Almeida e Oliveira (2017), a concepção reducionista do atual EM dificulta a formação para uma cidadania ampliada e elimina o ideal de uma educação na perspectiva universalizante, principalmente, no que tange à dimensão cultural-artística do conteúdo. Tais impactos promulgados por esta reforma geram uma crise na $\mathrm{EF}$, mas como?

Lançando mão das análises realizadas por Bracht (2001), Cariglio, Almeida e Oliveira (2017), que apontam que esta reforma mobiliza o campo da EF novamente acerca das discussões a respeito da sua legitimidade enquanto componente curricular. Desse modo, o fato de a reforma oferecer menos prestígio a EF parece ser uma tentativa de deslegitimar esta disciplina, colocando-a em uma crise. De acordo com Cariglio, Almeida e Oliveira (2017, p. 62):

Quando a lógica do neotecnicismo do projeto de liberal burguês se afirma de forma tão radical nas políticas educacionais, tal como vimos na contrarreforma do Ensino Médio, se instaura a ideia de que de que determinados componentes curriculares podem simplesmente desaparecer do currículo escolar. 
Nesse sentido, os autores supracitados ainda vão dizer que a EF escolar, por tratar de saberes vinculados ao universo das experiências e do cotidiano em detrimento daqueles advindos das disciplinas acadêmicas-científicas e teóricas-conceituais, apresenta dificuldade de se legitimar dentro de um "novo" sistema escolar público que é voltado basicamente para o mercado de trabalho onde as disciplinas de Matemática, Português e Inglês ganham destaque.

A tentativa de retirada da EF do arranjo curricular denota a ideia de que ela se configura como um apêndice dentro da escola; contudo, a sua reinserção no currículo não tranquiliza a área e, muito pelo contrário, parece propor uma "saída para a crise" da EF que a direcione no mesmo sentido do "novo" EM: uma disciplina de caráter prático, técnico, meritocrático e que forme sujeitos altamente competitivos.

\section{Precisamos falar sobre a crise!}

Este texto procurou analisar como o diagnóstico da crise sobre o Ensino Médio brasileiro tem resultado em propostas e "saídas" que prejudicam tanto os jovens que frequentam este espaço como a Educação Física escolar. Tal análise indica um retrocesso teórico das discussões do campo da sociologia da juventude e também o retorno do debate epistemológico do campo da EF, sobretudo no que tange ao seu alcance diante das práticas pedagógicas e curriculares da EF no EM. Além disso, a "saída" da crise com a criação do "novo" EM reforça o renascimento de uma crise no âmbito da juventude e da EF.

Crise esta que é caracterizada por um retorno de uma visão da juventude como uma fase da vida que deve ser preparada e "treinada" para a fase adulta; pelo retorno de uma visão da escola dualista que reforçará as desigualdades sociais por meio de um ensino técnico (para pobres) e um ensino propedêutico (para ricos) e; pela volta do debate da crise de legitimidade da EF dentro da escola, sobretudo no EM.

Essa instalação de crise na EF brasileira, segundo Molina Neto et al (2017), pode ser um momento importante para a área refletir sobre a formação universitária dos seus professores, bem como sobre suas práticas pedagógicas e sobre as possíveis contribuições desta disciplina no que tange as experiências juvenis.

Gariglio, Almeida e Oliveira (2017) propõem algumas saídas para esta crise: entendem que é necessário revisitar as Diretrizes Curriculares Nacionais para o Ensino Médio (DCNEM) e as Orientações Curriculares do Ensino Médio bem como dialogar o EM e a EF tendo o trabalho como princípio educativo. Proposta semelhante é realizada por Bungenstab e Lazarrotti Filho (2017, p. 35) que discutem um modelo de escola que contenha o trabalho como mediação:

Nesse ponto, a EF pode ser uma disciplina fundamental para se pensar em um novo modelo escolar em uma sala de aula "outra", onde as práticas corporais sejam elemento central, fazendo com que o jovem compreenda sua realidade e seja capaz de transformá-la.

A citação acima corrobora com as ideias das Orientações Curriculares do Ensino Médio (BRASIL, 2006) que acreditam que, por meio das práticas corporais, os jovens podem realizar leituras do e no mundo. Para Gariglio, Almeida e Oliveira (2017, p. 68): "Uma Educação Física que, como linguagem, poderia ser uma excelente 'chave de leitura do mundo' a partir das relações de sociabilidades destes coletivos" fazendo com que os alunos tenham uma leitura ampliada e crítica da realidade. Para Dayrell (2007, p. 1125) a escola precisa:

[...] se perguntar se ainda é válida uma proposta educativa de massas, homogeneizante, com tempos e espaços rígidos, numa lógica disciplinadora, em que a formação moral predomina sobre a formação ética, em um contexto dinâmico, marcado pela flexibilidade e fluidez, de individualização crescente e de identidades plurais. 
A EF precisa "brigar" para não ser reduzida a espaços e tempos específicos dentro da escola, como quadras e pátios. Esta disciplina precisa gerar impactos no currículo do EM deixando de ser apêndice para acrescentar, de fato, na formação do jovem. Para tal, a leitura dos professores deve levar em consideração a realidade dos jovens estudantes, fazendo deles interlocutores do processo. Isso significa reconhecer a juventude nas suas múltiplas dimensões na busca de contribuir na construção das condições juvenis. Nesse sentido, talvez em um futuro próximo, poderemos afirmar que a Educação Física "faz" juventudes!?

\section{Referências}

ALMEIDA, F. Q.; BRACHT, V.; VAZ, A. Classificações epistemológicas na educação física: redescrições. Movimento (ESEFID/UFRGS), Porto Alegre, p. 241-263, ago. 2012. Disponível em: 〈http://www.seer.ufrgs.br/index.php/Movimento/article/view/27727/23457>. Acesso em: 11 mar. 2018.

ALMEIDA, F. Q.; VAZ, A. F. Do giro lingüístico ao giro ontológico na atividade epistemológica em Educação Física. Revista Movimento, Porto Alegre, v. 16, n. 03, p.11-29, jul./set. 2010.

BAUMAN, Z. Entrevista sobre educação: desafios pedagógicos e modernidade líquida. Tradução Neide L. de Rezende e Marcello Bulgarelli. Cadernos de Pesquisa, v. 39, n. 137, maio-ago. $2009 . \quad$ Disponível em: <http://www.scielo.br/scielo.php?pid=S010015742009000200016\&script=sci_arttext >. Acesso em: 15 jun. 2014.

BAUMAN, Z. Sobre educação e juventude. Rio de Janeiro: Jorge Zahar, 2013.

BASTIEN, C. A noção de crise no senso comum e nas ciências sociais. Vértice, n. 14, p. 11$19,1989$.

BUNGENSTAB, G. C. Dando voz aos estudantes na cidade de Goiânia/GO: investigações sobre a "crise" entre os jovens e o ensino médio. 2016. $171 \mathrm{f}$. Tese (Doutorado em Sociologia) - Universidade Federal de Goiás, Goiânia, 2016.

BUNGENSTAB, G. C.; LAZZAROTTI FILHO, A. A Educação Física no "novo" Ensino Médio: a ascensão do notório saber e o retorno da visão atlética e "esportivizante" da vida. Motrivivência, Florianópolis, v. 29, n. 52, p. 19-37, $\quad$ set. 2017. https://doi.org/10.5007/2175-8042.2017v29n52p19.

BRACHT, V. Saber e fazer pedagógicos: acerca da legitimidade da educação física como componente curricular. In: CAPARROZ, F. E. (Org). Educação Física escolar: Política, investigação e intervenção. Vitória: Proteoria, 2001. p. 67-80.

BRASIL. Ministério da Educação. Secretaria de Educação Básica. Orientações Curriculares para o Ensino Médio. Linguagens, Códigos e suas tecnologias, Volume 1, 2006. 
CARRANO, P. C. R. O ensino médio na transição da juventude para a vida adulta. In: Ferreira, C, A.; Peres, S. O.; Braga, C. N.; Cardoso, M. L. M. (Org.). Juventude e iniciação científica: políticas públicas para o ensino médio. 1. ed. Rio de Janeiro: EPSJV, UFRJ, 2011.

COMTE, A. Discurso sobre o espírito positivo. São Paulo: Abril Cultural, 1983.

DAYRELL, J. O jovem como sujeito social. Revista Brasileira de Educação, Rio de Janeiro, n. 24. p. 4-13, dez. 2003.

DAYRELL, J. Por uma sociologia da juventude. Centro de referência virtual do professor, p.1-14, set. 2010. Disponível em: <

http://crv.educacao.mg.gov.br/sistema_crv/banco_objetos_crv/\%7BD6965967-E284-4B3CB005-A28EBBBE3B35\%7D_Sociologia\%20da\%20Juventude.pdf > Acesso em: 6 jan. 2014.

DAYRELL, J. A escola faz juventudes? Reflexões em torno da socialização juvenil. Ed. Soc., Campinas, v. 28, n. 100, p. 1105-1128, out. 2007. Disponível em <http://www.cedes.unicamp.br>. Acesso em: 5 jun. 2014.

DUBET, F. Sociologia da experiência. Lisboa: Instituto Piaget, 1994.

EISENSTADT, S. N. De geração a geração. São Paulo: Perspectiva, 1956.

FENSTERSEIFER, P. E. A Educação Física na crise da modernidade. Ijuí: UNIJUÍ, 2001.

FENSTERSEIFER, P. E. Epistemologia e prática pedagógica. Revista Brasileira de Ciências do Esporte, Campinas, v. 30, n. 3, p.203-214, 2009. Disponível em:

<http://www.rbce.cbce.org.br/index.php/RBCE/article/view/258/367> Acesso em: 2 out. 2017.

GARIGLIO, J. Â.; ALMEIDA JUNIOR, A. S.; OLIVEIRA, C. M. O "novo" Ensino Médio: implicações ao processo de legitimação da Educação Física. Motrivivência, Florianópolis, v. 29, n. 52, p. 53-70, set. 2017. https://doi.org/10.5007/2175-8042.2017v29n52p53

GROPPO, L. A. A juventude: ensaios sobre sociologia e história das juventudes modernas. Rio de Janeiro: Difel, 2000.

GROPPO, L. A. Dialética das juventudes modernas e contemporâneas. Revista de Educação do Cogeime, n. 25, p. 9-22, dez. 2004. Disponível em: <

http://www.scielo.cl/pdf/udecada/v18n33/art02.pdf > Acesso em: 7 out. 2014.

LIMA, H. L. A. de. Pensamento epistemológico da educação física brasileira: das controvérsias acerca do estatuto científico. Revista Brasileira de Ciências do Esporte, v. 21, n. 2, 2000 .

MOEHLECKE, S. O ensino médio e as novas diretrizes curriculares nacionais: entre recorrências e novas inquietações. Revista Brasileira de Educação, Rio de Janeiro, v. 17, n. 49, p. 39-50, 2012. 
MOLINA NETO, V. et al. A Educação Física no Ensino Médio ou para entender a Era do Gelo. Motrivivência, Florianópolis, v. 29, n. 52, p. 87-105, set. 2017. https://doi.org/10.5007/2175-8042.2017v29n52p87.

PAIS, J. M. Culturas juvenis. Lisboa: Imprensa Nacional Casa da Moeda, 1993.

REIS, R. Juventudes no ensino médio: os sentidos atribuídos à escola e aos planos de futuro. Latitudes, São Paulo, v. 6, n.1, p. 131-155, jul./set. 2012.

ROUSSEAU, J. Emílio ou da educação. 2 ed. São Paulo: Difusão Européia do Livro, 1973.

SOUSA, F. O que é ser adulto? A sociologia da adultez. Porto: Memoria Imaterial, 2010.

Recebido em: 18/03/2018

Revisado em: 19/06/2018

Aprovado em: 28/06/2018

Endereço para correspondência:

gabrielcarv@msn.com

Gabriel Carvalho Bungenstab

Universidade Estadual de Goiás

Universidade Estadual de Goiás, UEG/Eseffego.

Avenida Anhanguera - de 3076 a 4214 - lado par

Setor Leste Vila Nova

74643010 - Goiânia, GO - Brasil 